\title{
Estimativa do déficit de investimentos em saneamento em Minas Gerais
}

\section{Vitor Carvalho Queiroz Nilo de Oliveira Nascimento}

Submetido em: 07/09/16 Revisado em: 24/10/16 Aprovado em: 25/10/16
Resumo: O Plano Nacional de Saneamento Básico (Plansab) estimou que a necessidade de investimentos para um horizonte de 20 anos, entre 2014 e 2033 , seria de 304 bilhóes de reais para os sistemas de abastecimento de água e esgotamento sanitário, tanto para expansão quanto para reposição da infraestrutura, em áreas urbanas e rurais. $\mathrm{O}$ presente estudo pretende identificar o déficit de recursos para realização de investimentos nos sistemas de abastecimento de água e esgotamento sanitário no Estado de Minas Gerais, através da comparação entre a necessidade e a capacidade de investimento dos prestadores dos serviços. Os resultados mostram um déficit de 1,8 bilhóes de reais por ano no caso da meta de universalização ser estipulada para o ano de 2022; 974 milhóes por ano para 2028 e 740 milhóes por ano para 2033. Esses números evidenciam que o desafio para a universalização do abastecimento de água é a reposição e para o esgotamento sanitário é a expansão. $\mathrm{O}$ trabalho busca contribuir não só para a estimativa de valores de necessidade, capacidade e déficit de investimentos, mas também para a tentativa de estabelecer uma sistemática de cálculo de déficit para outros estados ou até mesmo outras escalas subnacionais de planejamento.

Palavras-chave: Universalização; Investimentos; Água; Esgoto.
Abstract: The Brazilian National Sanitation Plan (Plansab) evaluated the investments need for twenty years, between 2014 and 2033, in 304 billions of Brazilian reais for water supply and sewerage systems, both for expansion and replacement of infrastructure, in urban and rural areas. This study intend to identify the investments gap in the water supply and sewerage systems in State of Minas Gerais, through the comparison between investments needs and current capacity. The results show a gap of 1,8 billions per year for the universalization target in 2022; 974 millions per year for 2028 and 740 millions for 2033. The numbers found also show that the main challenge for water supply is replacement of infrastructure assets and for sewerage is the expansion. This paper aims contribute not only for the investments needs, capacity and gap valuation, but also for the attempt to establish a systematic of calculation for other states or subnational regions of planning.

Keywords: Universalization; Investments; Water supply; Sewerage.

\section{INTRODUÇÃO}

O setor de saneamento é caracterizado pela intensidade de capital em razão da robusta infraestrutura necessária para o alcance de seus fins. No Brasil, observa-se que, historicamente, os investimentos realizados foram significativamente inferiores àqueles necessários para a universalização dos serviços de abastecimento de água e esgotamento sanitário. Isto, aliado a outros fatores, retrata uma conjuntura em que há enorme descompasso entre a política pública de saneamento e o padrão atual de desenvolvimento do país. (HELLER, 2012)
Ao analisar brevemente a trajetória dos investimentos em saneamento no Brasil identifica-se que até a década de 1960 do século XX, os investimentos foram realizados pontualmente e de forma desarticulada. (JUSTO, 2004) Durante a década de 1970 , as taxas de investimento mantiveram-se estáveis em relação ao PIB, em torno de $0,30 \%$, o que ocasionou a elevação das coberturas domiciliares de redes, majoritariamente de água, uma vez que quase a totalidade dos recursos foram utilizados para esse sistema. Na década de 1980, percebe-se uma redução dos diferenciais entre os recursos investidos em água e esgoto, com aumento relativo do último. $\mathrm{O}$ reflexo 
desta mudança ocorreu na década seguinte, com o aumento na cobertura de redes de esgoto. Na década de 1990, a taxa de investimento média apresentou queda acentuada na sua primeira metade, seguida por um aumento até 1998 , sucedida por nova queda (REZENDE; HELLER, 2008). Na primeira década dos anos 2000, a taxa de investimento em relação ao PIB apresentou uma trajetória crescente. Em 2003, a referida taxa ultrapassou o percentual de $0,10 \%$, atingindo seu ápice em 2009, com pouco mais de $0,2 \%$ (BRASIL, 2014). No entanto, os valores apresentam queda desde então, o que pode apontar uma nova inflexão na política de saneamento por parte do governo federal.

Os custos globais de manutenção e desenvolvimento da infraestrutura de saneamento nos países da OCDE e dos BRICs variam entre 0,35 e 1,2\% do seu PIB. Isso corresponde a uma necessidade de 1.037 bilhôes de dólares até 2025 contra uma projeção de investimento de 576 bilhóes de dólares anuais (OCDE, 2011a). Em outro estudo da OCDE (2011b), foram comparadas as necessidades em diferentes setores da infraestrutura. A necessidade do saneamento supera bastante outros setores intensivos em capital, como rodovias e distribuição e transmissão de energia elétrica. (OCDE, 2007)

Apesar de já terem alcançado a universalização, os países desenvolvidos deparam-se com enormes custos de modernização e melhoria nos seus sistemas, situação agravada pelas crescentes exigências regulatórias de saúde e meio ambiente. (OCDE, 2011a)

Segundo um relatório recente da Conviri, a agência italiana de recursos hídricos, o país necessita investir 50 bilhôes de euros nos próximos 20 anos, principalmente em reduçáo de perdas e tratamento de esgoto. Já a França e o Reino Unido precisam aumentar os gastos de saneamento em relação ao PIB em 20\% para manter os níveis de serviço; o Japão e a Coreia do Sul em mais de 40\%. (OCDE, 2011a)

Rosenberg (2013) relata o envelhecimento da infraestrutura de água e esgoto no Canadá. Existem diversos estudos que apontam valores distintos da necessidade para reposição da infraestrutura, mas há um consenso de que, em um futuro próximo, haverá necessidade significativa de novos investimentos para substituir a infraestrutura envelhecida e atender à demanda de novos avanços.
Recentemente, nos Estados Unidos, aspectos relativos à infraestrutura hídrica têm ganhado crescente atenção por parte dos formuladores de políticas públicas e dos legisladores devido à uma combinação de diversos fatores (COPELAND; TIEMANN, 2010):

- atendimento à requisitos regulatórios;

- financiamento da infraestrutura de reparo e substituição;

- segurança; e

- mudança na dinâmica no nível federal sobre "quem deve e pode pagar".

A Agência de Proteção Ambiental norte-americana conduziu pesquisas iniciais sobre necessidade de capital para investimentos em sistemas de água em 1995 e 1999. Em 2003, em decorrência da terceira versão da pesquisa, estimou a necessidade em 276,8 bilhôes de dólares para cumprir os requisitos da regulação e garantir o fornecimento de água potável de maneira segura. O estudo mais recente indica uma necessidade de aproximadamente 334,8 bilhóes de dólares para o período compreendido entre 2007 e 2026. Para os sistemas de esgotamento sanitário, a última pesquisa feita em 2008, estimou em 322 bilhóes de dólares o montante necessário. Além dessas pesquisas, foi feito ainda um estudo sobre o déficit de recursos, calculado como a diferença entre a necessidade e o quantitativo realmente investido, que mostrou um enorme desafio para o país. (COPELAND; TIEMANN, 2010)

Usualmente, as estimativas referem-se apenas aos investimentos necessários para assegurar a prestação de serviços de abastecimento de água e esgotamento sanitário de forma confiável e de acordo com os padróes de saúde e meio ambiente. Todavia, investimentos adicionais em infraestrutura podem ser considerados como uma ação significativa no sentido de minimizar os impactos ocasionados pelas mudanças climáticas, a exemplo da disseminação de plantas de dessalinização, alteamento de barragens e de projetos de reuso da água. No entanto, é preciso atentar para o fato de que tais medidas podem elevar ainda mais a necessidade de investimentos, que já se encontra em patamar elevado. (DECKER, 2015) 
O Plano Nacional de Saneamento Básico (Plansab) estimou que a necessidade de investimentos para um horizonte de 20 anos, entre 2014 e 2033, seria de 304 bilhóes de reais para os sistemas de abastecimento de água e esgotamento sanitário, tanto para expansão quanto para reposição da infraestrutura, em áreas urbanas e rurais. Aproximadamente $30 \%$ deste valor refere-se à reposição de ativos. Cerca de 23 bilhôes de reais são referentes às áreas rurais. E do montante total, 68 bilhôes, cerca de $20 \%$, deverão ser destinados às açôes estruturantes. Ainda está previsto um valor adicional de 112 bilhóes de reais para açóes estruturantes de gestão que não estão relacionadas a nenhum componente específico, mas que atendem aos quatro componentes. (BRASIL, 2014)

Percebe-se, portanto, que a necessidade advém não só da demanda de expansão para suprir o déficit de cobertura, como também da demanda pela contínua reposição dos ativos ao final de sua vida útil. Diante da ínfima cobertura existente nas áreas rurais, o saneamento rural possui, proporcionalmente, uma demanda ainda maior. As açóes estruturantes, que segundo o Plansab visam a melhoria da gestão e da prestação pública dos serviços, e consistem em medidas de assistência técnica e capacitação e açôes de desenvolvimento científico e tecnológico, são fundamentais já que assegurarão a sustentabilidade da prestação dos serviços ao longo do tempo.

Analisando o tema, Queiroz, Souza e Bortolini (2015) realizaram uma adaptação da metodologia utilizada no Plansab com o intuito de identificar a necessidade de investimentos dos municípios atendidos pela concessionária estadual em Minas Gerais - a Copasa. Para atingir a universalização em 2033, foram encontrados valores da ordem de 25 bilhóes de reais; destes, 14 bilhóes seriam destinados para o sistema de água e 11 bilhóes para o sistema de esgoto, resultando em uma média de 1,3 bilhão por ano.

À vista do exposto, o presente estudo pretende identificar o déficit de recursos para realização de investimentos nos sistemas de abastecimento de água e esgotamento sanitário no Estado de Minas Gerais, através da comparação entre a necessidade e a capacidade de investimento dos prestadores dos serviços. Dessa maneira, pretende-se apresentar uma contribuição ao tema, tão escasso na literatura, além de subsidiar futuras pesquisas e estudos relacionados a instrumentos de políticas públicas de saneamento.

\section{MATERIAL E MÉTODOS}

Para avaliar o déficit de investimentos foram feitos cálculos de estimativa da necessidade de investimentos e da capacidade de realização de investimentos. Para os cálculos foram utilizadas como fontes o SNIS e o banco patrimonial da Copasa e como ferramenta, um modelo de estimação da necessidade de investimentos.

\section{Necessidade de investimento}

A necessidade de investimentos nos segmentos de abastecimento de água e esgotamento sanitário constitui a soma dos investimentos necessários para expansão e para reposição desses sistemas.

Tanto para estimação da necessidade de investimentos em expansão quanto em reposição utilizou-se como apoio um modelo desenvolvido no âmbito do Programa de Modernização do Setor de Saneamento (2003) pelo consórcio JNS/Aqua-Plan e adaptado para utilizaçáo no Plansab. $\mathrm{O}$ modelo citado gera resultados de necessidade de investimentos por município, dessagregando os resultados entre áreas urbanas e rurais e entre os serviços de produção de água, distribuição de água, coleta de esgoto e tratamento de esgoto. No entanto, ainda que ele possa ser utilizado em diferentes escalas e níveis de agregação, as análises dos resultados devem ser sempre realizadas com base em valores agregados, e nunca município a município (REZENDE, 2011). Queiroz, Souza e Bortolini (2015) fizeram uma aplicação do modelo para estimar a necessidade de investimentos de diversos municípios de Minas Gerais tendo como elemento de agregação a prestação de serviços pela Concessionária Estadual e apontaram que sua aplicação em escala regional pode ser útil para subsidiar instrumentos de planejamento e regulação.

No que se refere à população, foram utilizados pelo modelo a classificação do IBGE quanto à situação dos domicílios (urbanos ou rurais). Cabe apontar uma referência específica do modelo no que diz respeito ao atendimento às populaçôes rurais: são consideradas 
apenas as populaçóes rurais aglomeradas em pequenas localidades. Para este efeito, considera-se que 50\% da população rural encontra-se nesta situação. Os próximos tópicos descrevem com mais detalhes os procedimentos envolvidos para o cálculo da necessidade em expansão e reposição.

\section{Expansão}

\section{Demanda}

A demanda consiste, em suma, no referente à população não atendida no presente à qual se soma o crescimento populacional anual até o horizonte do estudo. Sendo assim, para o cálculo desse parâmetro, realiza-se um estudo de projeção populacional, além do cálculo da população não atendida. Para a projeção populacional, foi utilizado um método de estimativa desenvolvido por Madeira e Simóes (1972). Esse método adota a hipótese de há uma relação entre as populaçóes de regióes menores com a populaçáo total da região maior à qual pertencem. Assim, foi ajustada uma linha de tendência para projeção da população brasileira total (através de dados do IBGE) e as populaçóes estaduais e municipais foram obtidas através de coeficientes que expressam a dita relação. Para o cálculo da demanda, determinou-se o déficit de atendimento dos serviços de saneamento (distribuição de água, tratamento de água, coleta de esgoto, tratamento de esgoto, fossa séptica), ou seja, a quantidade total de habitantes no ano-base menos a quantidade de habitantes atendidos por cada serviço nesse mesmo ano. A demanda seria entáo este déficit acrescido do aumento da população no decorrer dos anos.

\section{Custo}

As Tabelas 1 e 2 abaixo apresentam os custos unitários dos sistemas de água e esgoto relativos ao estado de Minas Gerais. Para o presente estudo, os valores foram atualizados monetariamente para a data de agosto de 2015 com base no INCC (Índice Nacional de Custos da Construção).

Tabela 1 - Custos unitários dos sistemas de abastecimento de água (preços de ago./2015)

\begin{tabular}{l|c|c|c|c|c}
\hline $\begin{array}{l}\text { Porte do Município } \\
\text { (habitantes) }\end{array}$ & 0 a 5.000 & 5.001 a 50.000 & $\begin{array}{l}50.001 \mathrm{a} \\
200.000\end{array}$ & $\begin{array}{l}200.001 \mathrm{a} \\
1.000 .000\end{array}$ & $\begin{array}{l}1.000 .001 \mathrm{a} \\
20.000 .000\end{array}$ \\
\hline $\begin{array}{l}\text { Produção de água } \\
\text { (R\$/habitante) }\end{array}$ & 287,90 & 273,50 & 289,69 & 312,56 & 296,93 \\
\hline $\begin{array}{l}\text { Distribuição de água } \\
\text { (R\$/domicílio) }\end{array}$ & $1.884,35$ & $1.922,25$ & $2.503,72$ & $2.000,34$ & $2.040,57$ \\
\hline
\end{tabular}

Tabela 2 - Custos unitários dos sistemas de esgotamento sanitário (preços de ago./2015)

\begin{tabular}{l|c|c|c|c|c}
\hline $\begin{array}{l}\text { Porte do município } \\
\text { (habitantes) }\end{array}$ & 0 a 5.000 & 5.001 a 20.000 & $\begin{array}{c}20.001 \mathrm{a} \\
50.000\end{array}$ & $\begin{array}{c}50.001 \mathrm{a} \\
200.000\end{array}$ & $\begin{array}{c}200.001 \mathrm{a} \\
20.000 .000\end{array}$ \\
\hline $\begin{array}{l}\text { Rede de coleta de } \\
\text { esgoto (R\$/domicílio) }\end{array}$ & $3.976,37$ & $3.732,14$ & 4339,84 & $3.287,77$ & $3.085,84$ \\
\hline $\begin{array}{l}\text { Fossa Séptica } \\
\text { (R\$/domicílio) }\end{array}$ & $2.596,04$ & $2.596,04$ & $2.596,04$ & $2.596,04$ & $2.596,04$ \\
\hline $\begin{array}{l}\text { Tratamento de esgotos } \\
\text { (R\$/habitante) }\end{array}$ & 159,75 & 151,86 & 340,93 & 518,12 & 492,21 \\
\hline
\end{tabular}


Metas de atendimento e anos de projeto

Foram calculados os montantes necessários para o alcance da universalização do atendimento dos serviços de água e esgoto em três horizontes distintos, os anos 2022, 2028 e 2033. A escolha se deu em função do modelo utilizado, que possui a data final em 2033, os demais foram definidos como intervalos similares.

\section{Reposição}

A necessidade de investimento para reposição, por sua vez, foi calculada em duas etapas: na primeira

lançou-se máo do banco de dados patrimoniais da Copasa e na segunda aplicou-se novamente o modelo utilizado no estudo do Plansab.

Definiu-se então a vida útil dos ativos e, partindo-se da data de incorporaçáo dos mesmos ao banco patrimonial, foi possível prever a parcela de reposição por data para cada ativo. Com exceçáo das categorias Equipamentos, Instalações Elétricas e Estaçôes de Macromedição, cuja vida útil estabelecida é equivalente a 10 anos, determinou-se que a vida útil das estruturas componentes dos sistemas de abastecimento de água e de esgotamento sanitário é de 60 anos.

Cabe ainda mencionar que se optou por calcular a necessidade de investimentos para reposição, considerando-se que a reposição dos ativos não acontece integralmente logo que sua vida útil chega ao fim. Foi considerado que a reposiçáo acontece ao longo da vida útil do ativo (ao longo de 60 ou de 10 anos, conforme o ativo considerado). Além disso, foi estabelecido que a necessidade de reposiçáo de determinado ativo é crescente ao longo do seu tempo de operação, isto é, quanto maior a idade do ativo maior os gastos com reposição do mesmo, conforme a Equaçáo 1. Esse método foi proposto pelos próprios autores em virtude do caráter dinâmico, complexo e interdependente da infraestrutura que compôe os sistemas de água e esgoto, que não é reposta de uma vez, mas por partes (ALEGRE \& COELHO, 2013):

$$
V r_{n}=\frac{V_{o c}}{V_{U}^{2}} \cdot n V r_{n}=\frac{V_{o c}}{V_{U}^{2}} \cdot n
$$

em que

$V r_{n} V r_{n}=$ valor de reposição no ano $\mathrm{n}$ do ativo;

$V_{O C} V_{O C}=$ valor original Corrigido do ativo;

$V_{U} V_{U}=$ vida útil do ativo; $\mathrm{e}$

$n n=$ número de anos do ativo desde a sua incorporação.

Feita a primeira etapa, partiu-se entáo para a aplicaçáo do modelo de estimaçáo da necessidade de investimentos. Assim como para a expansão, foi possível escolher os anos intermediários para análise e as metas de reposição dos ativos. As metas de reposição adotadas, que foram baseadas no Plansab, são apresentadas na Tabela 3.

De posse dos valores referentes à necessidade de investimentos para reposição por município, calculados pelo modelo, foram alocados proporcionalmente a estes os valores calculados com base no banco patrimonial da Copasa.

Por fim, os valores correspondentes à necessidade de investimentos projetada foram corrigidos monetariamente para a data base de agosto de 2015 através do INCC.

Tabela 3 - Metas de reposição de ativos

\begin{tabular}{l|c|c|c|c|c|c}
\hline & \multicolumn{3}{c}{ Abastecimento de água } & \multicolumn{4}{c}{ Esgotamento Sanitário } \\
\cline { 2 - 7 } Metas de Reposição (\%) & 2022 & 2028 & 2033 & 2022 & 2028 & 2033 \\
\hline Universo urbano & 10 & 20 & 40 & 8 & 15 & 30 \\
\hline Universo rural & 9 & 18 & 35 & 7 & 14 & 25 \\
\hline
\end{tabular}




\section{Capacidade de investimento}

A partir dos valores de investimentos realizados em anos antecedentes, estimou-se a capacidade de investir de cada município. Foi feito um levantamento dos investimentos contratados, tanto pelo prestador quanto pelo município e pelo governo do Estado, nos anos de 2006 a 2013, de todos os municípios mineiros que responderam ao SNIS nesses anos. Esses valores foram, então, atualizados com base no INCC para a data base de agosto de 2015 .

Feito isso, calculou-se a média do valor investido nos sistemas de abastecimento de água e esgotamento sanitário ao longo dos anos. Assumiu-se, por fim, que a média calculada corresponde à capacidade de realizar investimentos de cada município. Por fim, o déficit de recursos é calculado pela diferença entre a necessidade e a capacidade.

\section{RESULTADOS E DISCUSSÃO}

\section{Necessidade de investimentos}

$\mathrm{Na}$ Tabela 4 são apresentadas a necessidade de investimentos total e anual, respectivamente, para o alcance da universalizaçáo dos serviços de abastecimento de água e esgotamento sanitário no Estado de Minas Gerais, para diferentes horizontes: 2022, 2028 e 2033.

É importante lembrar que a análise dos horizontes deve ser feita sempre entre o ano base, 2015, e a meta de universalização. Portanto os valores não são cumulativos. Assim, para atingir a universalização em 2022 são necessários um pouco mais de 27 bilhóes de reais, valor que representa aproximadamente 3,4 bilhóes de reais por ano. No caso da meta de universalização estipulada em 2028, o montante total é de 35,8 bilhóes de reais ou 2,5 bilhóes por ano. E, para a meta de 2033, o total é de 44,17 bilhóes totais, cerca de 2,3 bilhóes por ano. Os valores anuais necessários representam entre $0,47 \%$ e $0,70 \%$ do PIB de Minas Gerais.

Nota-se, também, em comparação com os investimentos necessários para o sistema de abastecimento de água, que a necessidade de recursos para expansão do sistema de esgotamento sanitário é significantemente superior ao primeiro, enquanto os recursos necessários para reposição são inferiores. Essa constatação evidencia a dimensão do déficit de coleta e tratamento de esgoto em relação aos serviços de água.

Embora a análise dos horizontes de forma contínua demande cautela, é interessante avaliar a evolução da participação de cada necessidade. A expansão de água representa aproximadamente $20 \%$ da necessidade total para o horizonte de 2022, e se mantém estável para os demais horizontes. Já a reposição de água representa $10 \%$ em 2022 e salta para quase $20 \%$ em 2033. A expansão de esgoto representa $61 \%$ da necessidade em 2022 e diminui para $46 \%$ em 2033. A reposição de esgoto passa de 6,7\% em 2022 para 13\% em 2033. Esses números representam os desafios existentes em termos de necessidade, bem como sua evoluçáo ao longo do tempo. Atualmente, o grande desafio ainda é a expansão; todavia, com o decorrer do tempo, a tendência é que a reposição se torne o desafio. Esta inversão se dá em razáo da expectativa de que o acesso venha a ser universalizado e de que o envelhecimento natural da infraestrutura passe a demandar mais intervenção. Essa constatação é fundamental, uma vez que a mudança de prioridades necessita de adequação ao longo do tempo por parte das políticas públicas e das estratégias de financiamento.

Tabela 4 - Necessidade de investimentos total e anual (milhões de R\$)

\begin{tabular}{|c|c|c|c|c|c|c|c|}
\hline & & \multicolumn{2}{|c|}{2022} & \multicolumn{2}{|c|}{2028} & \multicolumn{2}{|c|}{2033} \\
\hline & & Total & Anual & Total & Anual & Total & Anual \\
\hline \multirow{3}{*}{ Água } & Expansão & 5.677 & 709 & 7.783 & 555 & 9.244 & 486 \\
\hline & Reposição & 2.852 & 356 & 5.451 & 389 & 8.531 & 449 \\
\hline & Subtotal & 8.529 & 1.066 & 13.234 & 945 & 17.775 & 935 \\
\hline \multirow{3}{*}{ Esgoto } & Expansão & 16.831 & 2.103 & 19.057 & 1.361 & 20.596 & 1.084 \\
\hline & Reposição & 1.828 & 228 & 3.532 & 252 & 5.803 & 305 \\
\hline & Subtotal & 18.659 & 2.332 & 22.589 & 1.613 & 26.400 & 1.389 \\
\hline Total & & 27.189 & 3.398 & 35.824 & 2.558 & 44.176 & 2.325 \\
\hline
\end{tabular}


$\mathrm{Na}$ Tabela 5, apresenta-se, ainda, a necessidade de investimentos desagregada por regiāo (urbana ou rural) e por subsistema (produção de água, distribuição de água, coleta de esgotos e tratamento de esgotos). Mostra, ainda, duas questóes principais: a comparação entre urbano e rural, e a comparação entre os subsistemas. A necessidade para as áreas rurais representa $19211 \%$ do total para o horizonte de 2022 e $8 \%$ para 2033. A queda reflete a tendência de diminuição da populaçáo rural nos próximos anos. Os percentuais de necessidade na área rural são bem próximos ao percentual da populaçáo, no entanto, ao considerar o menor custo dos sistemas de esgoto, percebe-se o déficit de cobertura na área rural é maior.

Com relação aos subsistemas, nota-se que a necessidade de alocação de recursos nos subsistemas de distribuição de água e coleta de esgotos é significativamente superior àquela necessária aos subsistemas de produção de água e tratamento de esgotos. Essa maior necessidade é devida, principalmente, ao alto custo que a construção de redes de distribuição e coleta demanda em relação à construção das demais unidades dos sistemas de abastecimento de água e esgotamento sanitário.
A Figura 1 mostra a necessita total de investimentos para o horizonte de 2033 em relaçáo ao PIB municipal, que evidencia a desigualdade regional dentro do

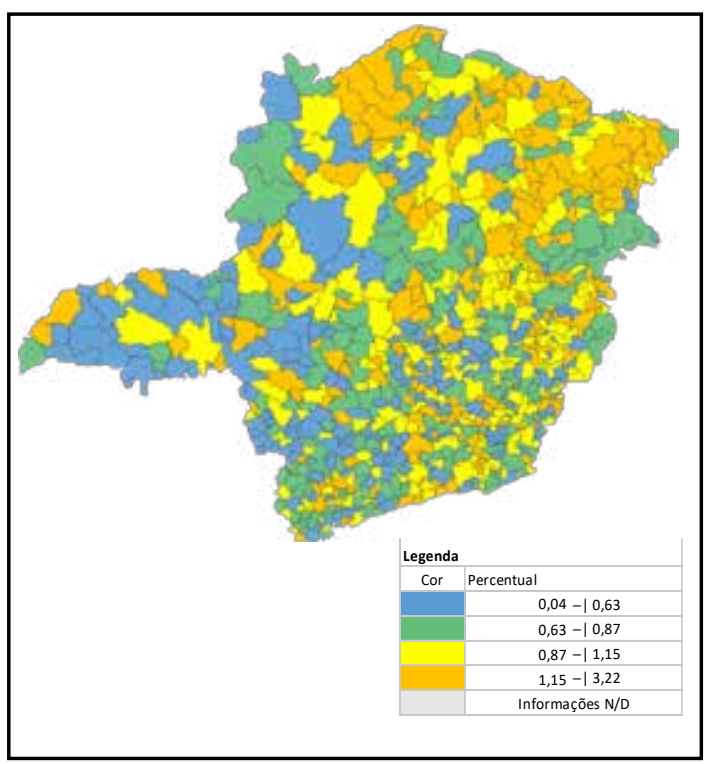

Figura 1 - Necessidade de investimento total em relação ao PIB municipal para o horizonte de 2033

Tabela 5 - Necessidade de investimentos em expansão (em milhões de R\$) desagregada por região e por subsistema

\begin{tabular}{|c|c|c|c|}
\hline & \multicolumn{3}{|c|}{2022} \\
\hline & Rural & Urbano & Total \\
\hline Produção de água & 368 & 1.558 & 1.927 \\
\hline Distribuição de água & 518 & 3.231 & 3.750 \\
\hline Coleta de esgoto & 1.390 & 9.663 & 11.053 \\
\hline Tratamento de esgoto & 167 & 5.609 & 5.777 \\
\hline \multirow[t]{3}{*}{ Total } & 2.444 & 20.063 & 22.508 \\
\hline & \multicolumn{3}{|c|}{2028} \\
\hline & Rural & Urbano & Total \\
\hline Produção de água & 356 & 2.134 & 2.490 \\
\hline Distribuição de água & 502 & 4.790 & 5.292 \\
\hline Coleta de esgoto & 1.328 & 11.657 & 12.985 \\
\hline Tratamento de esgoto & 157 & 5.914 & 6.071 \\
\hline \multirow[t]{3}{*}{ Total } & 2.344 & 24.496 & 26.840 \\
\hline & \multicolumn{3}{|c|}{2033} \\
\hline & Rural & Urbano & Total \\
\hline Produção de água & 347 & 2.501 & 2.849 \\
\hline Distribuição de água & 489 & 5.898 & 6.387 \\
\hline Coleta de esgoto & 1.287 & 13.064 & 14.351 \\
\hline Tratamento de esgoto & 151 & 6.093 & 6.244 \\
\hline Total & 2.276 & 27.557 & 29.833 \\
\hline
\end{tabular}


estado de Minas Gerais. Uma questão importante a ser avaliada é se o porte econômico do município determina a condição de acesso ao serviço, ou se, em alguma medida, o saneamento influencia na economia municipal. Embora com os dados apresentados não seja possível responder tal indagação, a hipótese é que ambos possuem uma relação de causa e consequência que gera um ciclo vicioso para o desenvolvimento do setor.

\section{Capacidade de investimentos}

A Tabela 6 apresenta a soma da capacidade de investimentos dos municípios mineiros nos anos de 2006 a 2013, bem como a média dos valores investidos nestes anos e o percentual em relaçáo ao PIB que essa média representa.
A Figura 2 mostra os investimentos realizados em relação ao PIB estadual com uma média de 0,36\% deste, apresentando uma queda entre 2006 e 2011, com exceção de 2008-2009, e uma leve recuperação nos dois anos seguintes.

Observa-se que a capacidade de investimentos no sistema de esgotamento sanitário é superior a capacidade de investimentos no sistema de abastecimento de água. Essa constatação indica que nos últimos anos os investimentos em esgotamento superaram os investimentos em água, em consonância com o déficit dos municípios mineiros.

Uma questão importante em relação à capacidade de investimentos é a participação da Copasa no mon-

Tabela 6 - Capacidade de investimentos e PIB (milhões de R\$). Valores atualizados a agosto de 2015

\begin{tabular}{l|c|c|c|c|c|c|c|c|c}
\hline \multicolumn{2}{r}{2006} & 2007 & 2008 & 2009 & 2010 & 2011 & 2012 & 2013 & Média \\
\hline Água & 829 & 795 & 708 & 886 & 673 & 549 & 493 & 529 & 697 \\
\hline Esgoto & 915 & 920 & 721 & 989 & 915 & 710 & 812 & 986 & 888 \\
\hline Total & 1.744 & 1.715 & 1.430 & 1.875 & 1.588 & 1.259 & 1.305 & 1.515 & 1.585 \\
\hline Valor PIB & 356.958 & 383.956 & 424.504 & 413.487 & 477.905 & 493.133 & 486.918 & 491.301 & 441.020 \\
\hline \% PIB & 0,49 & 0,45 & 0,34 & 0,45 & 0,33 & 0,26 & 0,27 & 0,31 & 0,36 \\
\hline
\end{tabular}

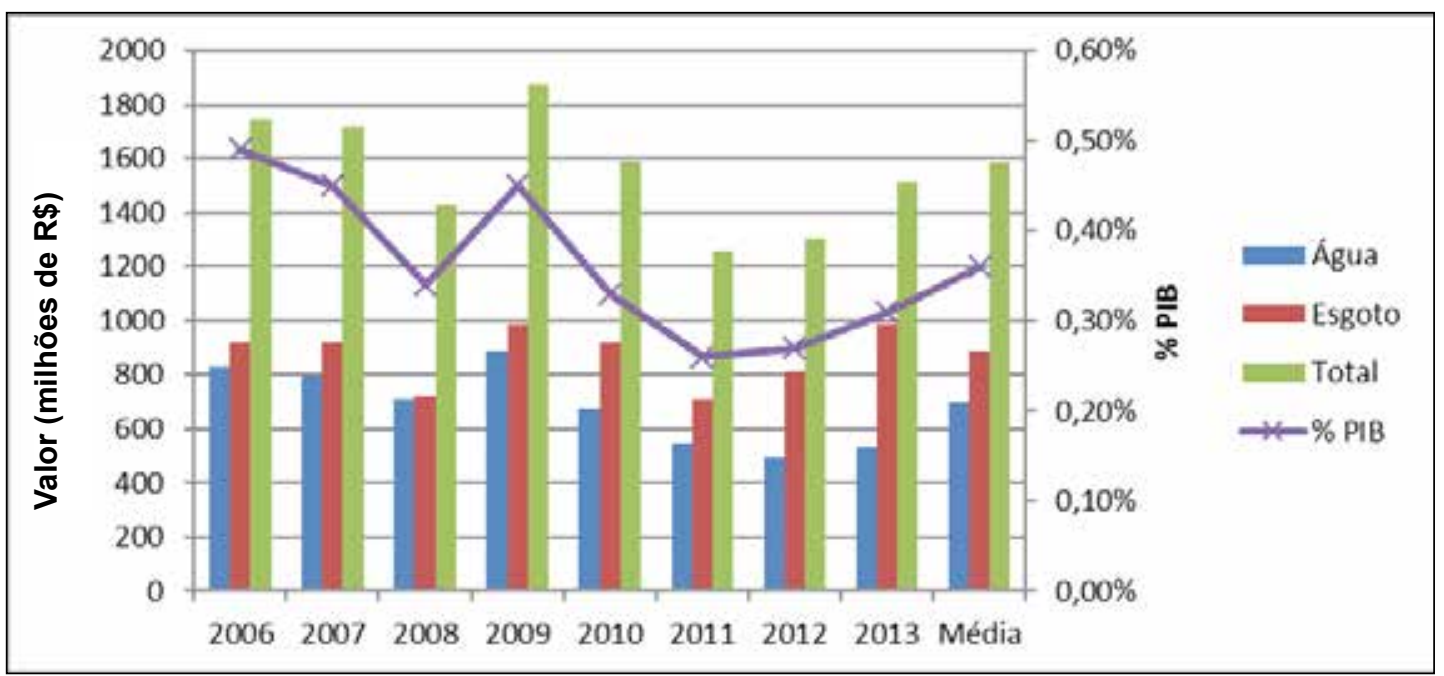

Figura 2 - Capacidade de investimentos (milhões de $\mathbf{R} \$$ ) e porcentagem do PIB 
tante total. Depreende-se que a capacidade estadual é mais influenciada pela conjuntura do prestador do que pela conjuntura nacional, embora aquela também seja influenciada por esta. A trajetória dos investimentos realizados pela Copasa em relação aos investimentos estaduais pode ser visualizada na Figura 3 , na qual se observa que o percentual dos investimen194 tos da Copasa em relação ao total do Estado apresenta uma tendência de queda. Déficit de investimentos

A Tabela 7 apresenta a diferença entre a necessidade

de investimentos e a capacidade de investimentos, denominado déficit de investimentos.

Os resultados mostram um déficit de 1,8 bilhóes de reais por ano no caso da meta de universalização ser estipulada para o ano de 2022; nesse cenário, os investimentos teriam mais que dobrar no Estado para alcançar a meta, hipótese improvável. O déficit diminui para 974 milhóes por ano para 2028 e 740 milhóes por ano para 2033, ou seja, um pouco mais factíveis, embora ainda represente necessidade de aumentos significativos dos investimentos em relação a capacidade atual. Um aspecto relevante é a proporção do déficit por sistema de água e esgoto em relação ao total. Enquanto para o ano de 2022 a participação do sistema de água é aproximadamente $20 \%$, no ano de 2028 é $25 \%$ e no ano de 2033 é de $32 \%$. Isso ilustra, ainda uma vez o envelhecimento da infraestrutura de água e a necessidade de reposição. A Figura 4 mostra a relaçáo entre o montante total do déficit e da necessidade por sistema e por horizonte. Os valores de déficit mostram a delicada situação do

Tabela 7 - Déficit de investimentos total e anual (em milhões de R\$)

\begin{tabular}{|c|c|c|c|c|c|c|}
\hline & \multicolumn{2}{|c|}{2022} & \multicolumn{2}{|c|}{2028} & \multicolumn{2}{|c|}{2033} \\
\hline & Total & Anual & Total & Anual & Total & Anual \\
\hline Água & 2.951 & 369 & 3.472 & 248 & 4.526 & 238 \\
\hline Esgoto & 11.559 & 1.445 & 10.164 & 726 & 9.536 & 502 \\
\hline Total & 14.510 & 1.814 & 13.636 & 974 & 14.063 & 740 \\
\hline
\end{tabular}

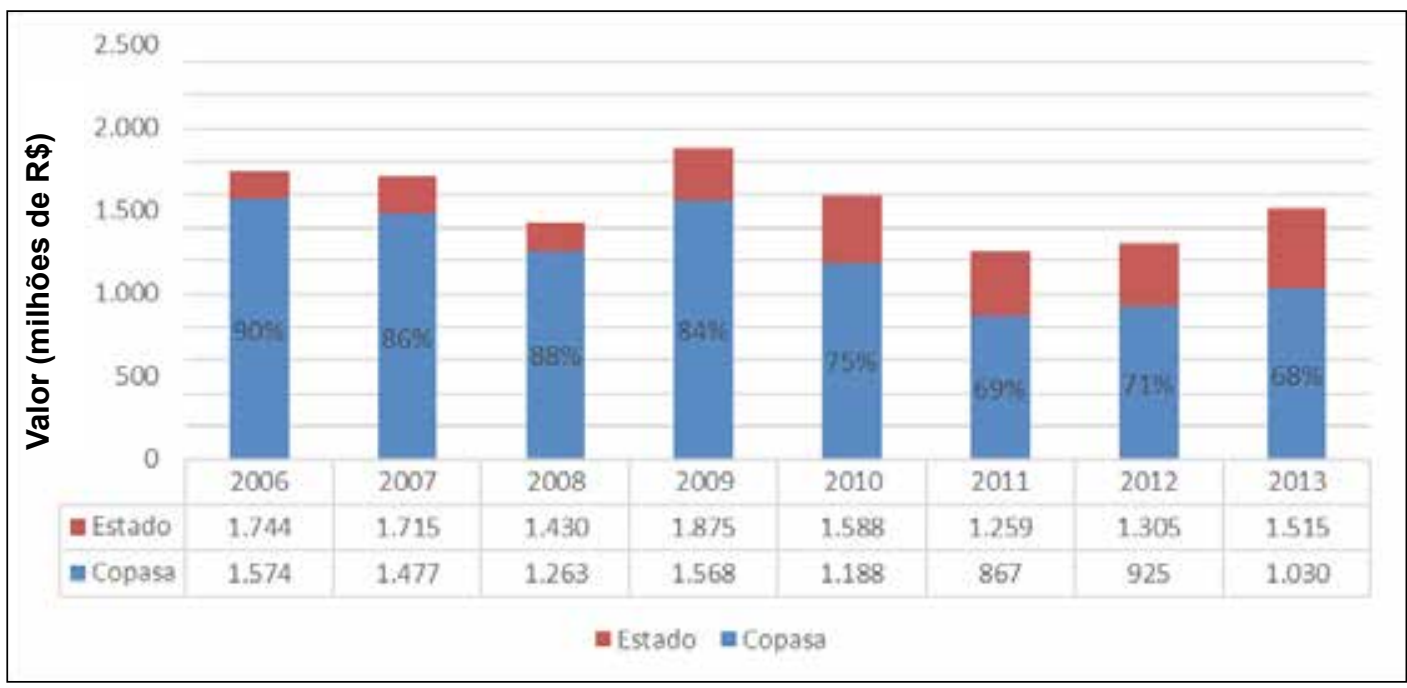

Figura 3 - Relação investimentos estaduais e da Copasa 


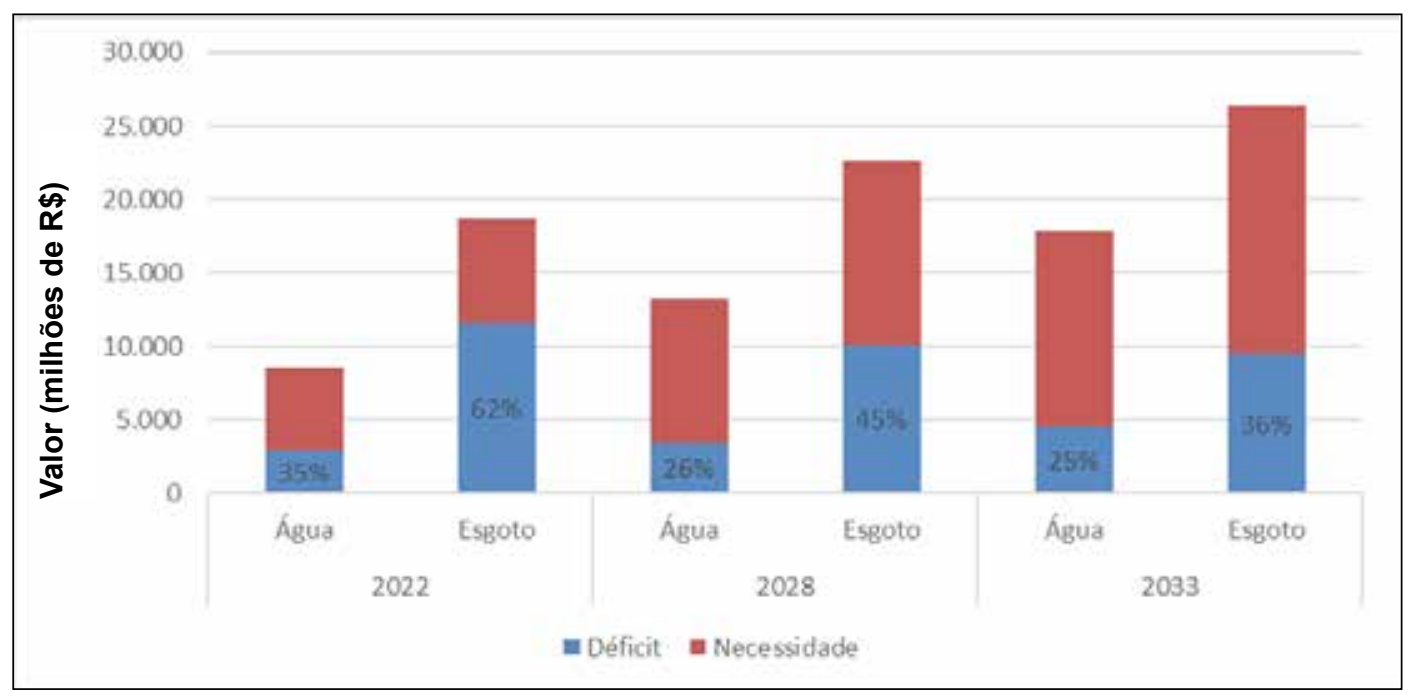

Figura 4 - Relação déficit e necessidade de investimentos por sistema horizonte

saneamento no Estado de Minas Gerais. Para alcançar a universalização nos horizontes de 2028 e 2033, os investimentos teriam que aumentar $61 \%$ e $47 \%$, respectivamente.

\section{CONCLUSÃO}

Os resultados evidenciam um enorme desafio para a universalização dos serviços de abastecimento de água e esgotamento sanitário, sendo cada um dos dois possuem outros desafios próprios. Para o sistema de esgoto, a expansão é ainda a principal ação a ser desenvolvida, diante do enorme déficit de acesso ao serviço. Já para o sistema de abastecimento de água, a necessidade de reposição da infraestrutura existente demanda mais recursos que a expansão.

A conturbada conjuntura política - econômica brasileira apresenta duas questóes que impactam diretamente na estimativa dos valores calculados no presente trabalho, quais sejam, a escassez hídrica e a situação econômica. $\mathrm{O}$ contexto de escassez hídrica vivenciado pelo país nos últimos anos, especialmente pela ampliação de seus efeitos de modo a abranger o sudeste brasileiro, pode influenciar tanto a necessidade quanto a capacidade estimadas. Pelo lado da necessidade, a possibilidade de prolongamento ou repetiçóes mais frequentes desses fenômenos no ciclo hidrológico reforça a importância de aumentar a segurança hídrica, que por sua vez requer mais investimentos na infraestrutura dos sistemas de abastecimento e açóes de conservação e recuperaçáo de mananciais. Pelo viés da capacidade, a necessidade de redução de consumo de água diminui as receitas dos prestadores, restringindo ainda mais a disponibilidade de recursos para investimento, por outro lado a demanda sobre a melhoria e expansáo dos sistemas também diminui com menor consumo.

Já a situação econômica atual, tende a provocar diminuiçáo nos recursos disponibilizados pelo orçamento público, afetando a capacidade de investimentos.

Todos os aspectos abordados apresentam um cenário de aumento no déficit de recursos, agravando ainda mais a demanda. De qualquer maneira, sejam as crises passageiras ou prolongadas, o contexto atual reforça a importância de mecanismos de financiamento do setor, como por exemplo, a instituição de fundos.

A estimativa da capacidade de realização de investimentos requer cautela uma vez que foca apenas nos recursos aplicados no setor e não necessariamente na disponibilidade, tampouco na capacidade de execução efetiva, uma vez que outros aspectos institucionais podem limitar a realização dos investimentos. 
O cálculo do déficit de recursos apresenta algumas limitaçóes decorrentes dos métodos de estimativa da necessidade e da capacidade, mas parece guardar coerência em termos de ordem de grandeza, embora seja difícil aprofundar a avaliação tendo em vista a inexistência de trabalhos similares, especialmente em escala regional e sobretudo para o Estado de Minas Gerais. Portanto, é possível afirmar que, ainda que com limitaçôes metodológicas, o presente trabalho busca contribuir não só para a estimativa de valores de necessidade, capacidade e déficit de investimentos, mas também para a tentativa de estabelecer uma sistemática de cálculo de déficit para outros estados ou até mesmo outras escalas de análise e planejamento. Espera-se que esses dados sirvam para subsidiar outros estudos e trabalhos futuros sobre temas correlacionados.

\section{Referências}

ALEGRE, H.: COELHO, S. T. Infrastructure asset management of urban water systems. In: OSTFELD, A. (Ed.). Water supply system analysis - Selected topics. Avi Ostfeld, 2013.

BRASIL. Lei no 11.445. Estabelece diretrizes nacionais para o saneamento básico. 5 jan. 2007.

BRASIL. Ministério das Cidades. Plano Nacional de Saneamento Básico (PLANSAB), 2014. Disponível em: <www.cidades.gov.br/ images/stories/ArquivosSNSA/Arquivos_PDF/plans ab_06-12-2013.pdf>. Acesso em: 3 out. 2015.

COPELAND, C.; TIEMANN, M. Water infrastructure needs and investment: Review and analysis of key issues. Washington, DC: Congressional Research Service, 2010.

DECKER, C. Modern economic regulation: An introduction to theory and practice. 1. ed. Cambridge: Cambridge Press, 2015

HELLER, L. Saneamento para todos com equidade: desafios contemporâneos para o Brasil. Disponível em: <http://www.assemae.org. br/arquivoArtigos/saneamentoparatodos.pdf>. Acesso em: 3 jul. 2012.

HELLER, L.; CASTRO, J. E. Políticas públicas e gestão de serviços de saneamento. Edição ampliada, Belo Horizonte: UFMG; Rio de Janeiro: Fiocruz, 2013.

JUSTO, M. C. D. de M. Financiamento do saneamento básico no Brasil: uma análise comparativa da gestão pública e privada. 2004. 165 f. Dissertação (mestrado em desenvolvimento econômico, espaço e meio ambiente) — Instituto de Economia, Universidade Estadual de Campinas, Campinas, 2004.

MADEIRA, J. L.; SIMÕES, C. C. S. Estimativas preliminares da população urbana e rural segundo as unidades da federação, de 1960/1980 por uma nova metodologia. Revista Brasileira de Estatística, v. 33, n. 129, p. 3-11, jan./mar. 1972.

OCDE. Social issues in the provision and pricing of water services. Paris: OECD Publishing, 2003.

OCDE. Infrastructure to 2030, volume 2, Mapping policy for water, electricity and transport. Paris: OECD Publishing, 2007.

OCDE. Innovative financing mechanisms for the water sector. Paris: OECD Publishing, 2010.

OCDE. Meeting the challenge of financing water and sanitation: Tools and approaches. Paris: OECD Publishing, 2011a. 
OCDE. Benefits of investing in water and Sanitation: An OECD perspective. OECD Publishing, Paris: OECD Publishing, 2011b.

PROGRAMA DE MODERNIZAÇÃO DO SETOR DE SANEAMENTO (PMSS). Dimensionamento das necessidades de investimentos para a universalização dos serviços de abastecimento de água e de coleta e tratamento de esgotos sanitários no Brasil. Brasília: Ministério das Cidades, Secretaria Nacional de Saneamento Ambiental. Programa de Modernização do Setor de Saneamento, 2003.

QUEIROZ, V. C.; SOUZA, G. A.; BORTOLINI, R. L. R. Metodologia para a identificação da necessidade de investimentos em expansão e reposição de sistemas de abastecimento de água potável e esgotamento sanitário. In: CONGRESSO BRASILEIRO DE REGULAÇÃO, 9. 2015, Brasília. Brasilia. ABAR, 2015.

REZENDE, S. C.; HELLER, L. O saneamento no Brasil: políticas e interfaces. 2. ed. rev. e ampl. Belo Horizonte: UFMG, 2008. 387 p.

REZENDE, S. C. (Org.). Investimentos em saneamento básico: análise histórica e estimativa de necessidades. Cadernos temáticos. (Vol. 5). In: HELLER, L.; MORAES, L. R. S.; BRITTO, A. L. N. P.; BORJA, P. C.; REZENDE, S. C. (Coord.). Panorama do saneamento básico no Brasil. Brasília: Ministério das Cidades, 2011.

ROSENBERG, M. W. "Do mar do Leste ao mar do Oeste". In: HELLER, L.; CASTRO, J. E. Políticas públicas e gestão de serviços de saneamento. Edição ampliada, Belo Horizonte: UFMG; Rio de Janeiro: Fiocruz, 2013. Cap. 15, p. 337-352.

Vitor Carvalho Queiroz Agência Reguladora de Serviços de Abastecimento de Água e Esgotamento Sanitário do Estado de Minas Gerais, Belo Horizonte, MG, Brasil vitorcqueiroz@yahoo.com.br

Contribuição do autor:

Desenvolveu a dissertação no programa de Saneamento, Meio Ambiente e Recursos Hídricos da UFMG que deu origem ao trabalho e redigiu o manuscrito.

Nilo O. Nascimento Universidade Federal de Minas Gerais, Belo Horizonte, MG, Brasil

niloon@ehr.ufmg.br

Contribuição do autor:

Orientou a dissertação e revisou o manuscrito. 